\title{
Mechanical behavior of masonry strengthened with coir fiber reinforced hydraulic cement mortar as surface plaster
}

\author{
M.N. Rupasinghe ${ }^{1}$, N. Sathiparan ${ }^{2 *}$ \\ ${ }^{1}$ University of Ruhuna, Department of Civil and Environmental Engineering, Hapugala, Galle, Srilanka \\ ${ }^{2}$ University of Jaffna, Department of Civil Engineering, Ariviyal Nager, Killinochchi, Srilanka
}

\begin{abstract}
Among the world population, a large proportion across the world still lives in masonry structures. The main problem in unreinforced masonry structures is its weakness against dynamic loads. This paper presents the proposal of the new retrofitting method using natural fiber added mortar as the surface plaster for masonry structures. Thus, the present study focuses on the experimental evaluation of a masonry prism with natural fiber reinforced mortar. The main reasons for the use of coconut coir as a natural fiber are richly available in locally and are fairly cheap. In this paper, the effects of coconut coir reinforced mortar mix, including different fiber content on compressive, shear and flexural bending behavior of masonry prisms is investigated through a comprehensive experimental study. Although this technique shows an average performance, due to the facts of low cost, local availability and relative simplicity of technique, this method may potentially be able to use to prevent the brittle collapse of unreinforced masonry structures under moderate seismic loading.
\end{abstract}

\section{Keywords}

Masonry; Natural fiber; Coconut coir; Seismic retrofitting; Ductility

Received: 21 February 2019; Accepted: 23 March 2019

ISSN: 2630-5763 (online) C 2019 Golden Light Publishing ${ }^{\circledR}$ All rights reserved.

\section{Introduction}

Among the world population, a large proportion of the world still lives in masonry structures due to its low cost and social and cultural acceptance. The main problem in unreinforced masonry structures is its vulnerability against dynamic loads, differential foundation settlements, etc. Most of these masonry structures have not been constructed considering seismic loads. Past earthquakes have provided enough evidence that many such buildings are seismic vulnerable and therefore an even moderate earthquake can result in massive death and casualties.

\footnotetext{
* Corresponding author

E-mail: nsakthiparan@yahoo.com
}

In the past years, the vast majority of these earthquakes were located at the boundaries of major tectonic plates which move relative to each other and those countries that unfortunately lie close to these boundaries were the most vulnerable ones as exemplified by the Japanese Islands, Indonesian Islands, and Philippines. Since Sri Lanka lies in the large Indo-Australian plate far away from any of the plate boundaries and therefore many people believe that it makes Sri Lanka safe from earthquakes. But according to the recent geological studies, it has found that a new plate boundary has formed separating the Indo Australian plate into the Indian plate and Australian 
plate and thus Sri Lanka need to be classified as a moderate earthquake prone area. These types of earthquakes are well enough to damage the nonengineering, masonry structures in Sri Lanka. Therefore, enhancing the strength capacity of masonry structures by providing proper retrofitting techniques against earthquakes is the main challenge. Numerous types of retrofitting techniques are available to strengthen the unreinforced masonry structures in the world. Most of them are highly expensive and high technology is required. But for a country like Sri Lanka, retrofitting techniques should be inexpensive construction materials, low-skill labor, and low technology.

The existing methods of retrofitting unreinforced masonry buildings such as surface treatment [1], post-tensioning [2], steel cage mesh retrofitting [3], polymer mesh retrofitting [4], plastic carrier bag mesh retrofitting [5], PP-bands mesh retrofitting [6], bamboo band mesh retrofitting [7]; use of strengthening materials on masonry structures improves its lateral strength. However, some referred strengthening materials are beyond the economic ability of the common people of the developing countries. Further, there is a scarcity of technical manpower in such countries [8].

Therefore, more research focused on the application of Fiber Reinforced materials added surface mortar as reinforcement technic for masonry. Fiber-reinforced mortar (FRM) generally is surface mortar containing uniformly distributed discrete fibers such as steel fiber, glass fiber, or natural fibers. Generally, unreinforced cementitious matrices as a surface plaster for masonry only improves the aesthetics, but not the structural behavior. However, fiber inclusion in cementitious matrices improves the post-crack behavior.

Maalej et al. [9] investigated the out-of-plane behavior of masonry panel, strengthened by ultraductile hybrid-fiber Engineered Cementitious Composite (ECC). The testing of masonry panels carried out by subject, to batch load, uniformly distributed load, and impact load. The results show that this strengthening method increased the ultimate load carrying capacity and improve the ductility of the masonry panel. In addition to that, ECC strengthens masonry panels showed an ability to resist multiple impact loading, where the reinforced wall failed catastrophically to single impact loading.

Kyriakides and Billington [10] evaluated the impact of fiber-reinforced concrete referred to as engineered cementitious composites (ECC) on masonry prisms and beams. Tests were conducted for compression and flexural behavior of a different type of fiber reinforced mortar strengthened masonry prisms and beams. Test results indicated that compressive strength and stiffness of ECC strengthened masonry increased by 45 and $53 \%$, respectively compared to those of plain masonry prisms. Flexural bending tests show that flexural strength and ductility of ECC strengthened masonry beams significantly increased, compared to the those of plain masonry beams. Dehghani et al. [11] investigated the behavior of fiber reinforced engineered cementitious composites (ECC) masonry infilled wall. The test results indicated that the ECC strengthened method increased the laterals strength and energy absorption capacity. Also, it has maintained the integrity of the masonry infill wall during lateral loading.

Najafgholipour et al. [12] investigated the outof-plane behavior of masonry prisms retrofitted by Polypropylene (PP) and steel fiber-reinforced mix. In this study, the effect of type and amount of fiber in the mortar mix and surface layer thickness on the flexural behavior of masonry prisms was investigated. The flexural behavior of masonry prisms was evaluated by a three-point loading test. The results of the tests show that masonry prisms retrofitted by a fiber reinforced mortar as surface layer increased flexural strength considerably. Also, the results show that applying steel fiber is more efficient than PP fibers. However, in this study, the effect of fiber reinforced mortar on the post-crack behavior of masonry was not investigated.

In most of the above-mentioned studies, the fiber materials used for reinforcement are industrial 
output and still relatively costly. Thus, the present study focuses on the experimental evaluation of a masonry prism with natural fiber reinforced mortar as surface plaster. Coconut coir used as a natural fiber, which is conventionally available at low cost. In this paper, the effects of coconut coir reinforced mortar on compressive, shear and flexural bending behavior of masonry prisms are investigated through a comprehensive experimental study.

For practical purposes, coconut coir reinforced mortar is used as surface plastering for masonry structures, therefore, an experimental program was executed to evaluate the effect of coconut coir reinforced mortar on masonry prisms. Coconut coir have some advantages like low density, less abrasiveness, and lower cost when compared to industrial fibers. Also, production of coconut coir is eco-friendlier and therefore it resulting in lesser health hazards compare with production of industrial fibers. As coconut coir will naturally degradable with limited environmental effect, coconut coir reinforced cementitious composites can be damp to landfills. Whereas industrial fibers have a negative environmental effect due to degradation pollution. The main aim of the present work is to prove the feasibility of using coconut coir reinforced hydraulic cement mortar surface plaster as a suitable and easier strengthening method for masonry structures.

\section{Experimental program}

\subsection{Materials}

For the tests, brick units $215 \times 105 \times 65 \mathrm{~mm}^{3}$ in size were used. The mortar was a mixture Portland cement, lime, and river sand ratio of 1:2:8. A uniform mortar thickness of $10 \mathrm{~mm}$ was adopted for joint mortar. The characteristics of the used materials are described below.

- Cement: Ordinary Portland cement (OPC) with physical and chemical properties are satisfied by Sri Lanka Standard SS855 [13].

- Sand: River sand, which was free from organic matter and not contain the clay, silt and fine dust.

- Lime: commercial grade hydrated lime.
- Coconut coir: Strength of masonry changes with the coir length [14]. Therefore, the optimum length is chosen as $25 \mathrm{~mm}$ as mentioned in Literature. Coir percentages were $0.125 \%, 0.25 \%, 0.5 \%$ and $0.75 \%$ of the total weight of cement, lime and sand excluding water weight.

During the construction of the masonry prisms, comprehensive material tests were conducted to monitor the mechanical properties of the materials. Bricks and mortar cubes were tested for compressive strength. Average values of the mechanical properties of brick, mortar and coconut coir are presented in Table 1.

\subsection{Mix design}

For easiness, the densities of each ingredient, including cement, sand, lime were converted the volume ratio to weight ratio. The tests were conducted for each mix proportion with different coir percentages to find out the water content for $160 \mathrm{~mm}$ slump to maintain the mix in workable condition. For the mortar mix, Cement: Lime: Sand in 1:2:8 (by volume) mix proportion which is mentioned as a mortar designation (iv) in Eurocode 6 [15] was used. The slump was maintained as 160 $\mathrm{mm}$ by adding sufficient water to make sure the mix is workable. Table 2 summarized the material mix and the amount of water required for each mortar type.

Table 1. Mechanical properties of brick, mortar and coconut coir [13]

\begin{tabular}{llr}
\hline (a) & Brick unit & \\
\hline & Density & $1363 \mathrm{~kg} / \mathrm{m}^{3}$ \\
& Compressive strength & $4.16 \mathrm{MPa}$ \\
& Young's modulus & $52.3 \mathrm{MPa}$ \\
& Water absorption rate & $8.30 \%$ \\
& Porosity & $11.30 \%$ \\
\hline (b) & Mortar & \\
\hline & Density & $1987 \mathrm{~kg} / \mathrm{m}^{3}$ \\
& Compressive strength & $2.79 \mathrm{MPa}$ \\
& Young's modulus & $200 \mathrm{MPa}$ \\
\hline (c) & Coconut coir & \\
\hline & Specific density & 1.15 \\
& Mean diameter & $20.7 \mu \mathrm{m}$ \\
& Mean length & $24.14 \mathrm{~mm}$ \\
\hline
\end{tabular}


Table 2. Mix proportion of materials for mortar mix

\begin{tabular}{llllll}
\hline $\begin{array}{l}\text { Coconut } \\
\text { coir }(\%)\end{array}$ & $\begin{array}{l}\text { Cement } \\
(\mathrm{kg})\end{array}$ & $\begin{array}{l}\text { Lime } \\
(\mathrm{kg})\end{array}$ & $\begin{array}{l}\text { Sand } \\
(\mathrm{kg})\end{array}$ & $\begin{array}{l}\text { Coconut } \\
\text { coir }(\mathrm{g})\end{array}$ & $\begin{array}{l}\text { Water } \\
(\mathrm{kg})\end{array}$ \\
\hline 0 & 1.0 & 1.10 & 8.67 & 0.0 & 1.30 \\
0.125 & 1.0 & 1.10 & 8.67 & 13.5 & 1.60 \\
0.250 & 1.0 & 1.10 & 8.67 & 26.9 & 1.67 \\
0.500 & 1.0 & 1.10 & 8.67 & 53.8 & 1.87 \\
0.750 & 1.0 & 1.10 & 8.67 & 80.8 & 2.00 \\
\hline
\end{tabular}

In their previous study, Sathiparan et al. [16] have investigated the strength and durability properties of coconut coir reinforced cement-lime mortar. To evaluate the effectiveness of the coconut fiber on surface plaster, a series of tests on mortar cubes and beams were conducted. From these tests, mortar properties such as density, porosity, water absorption, durability, strength were checked. Mortar properties with different coconut coir in the mix are summarized in Table 3. Research findings show that, although the initial strength of coconut coir mortar was almost the same as the control mortar, its residual strength was larger and sustained under larger deformations. The coconut coir reinforced mortar showed better performance in terms of residual strength, ductility and energy absorption.

\subsection{Specimens preparation and testing}

A total number of 54 masonry prisms as depicted in Fig. 1 and Fig. 2, were prepared. Three specimens are fabricated for each fraction of coconut coir reinforced mortar and bare case (no surface finishing). The joint mortar thickness was approximately $10 \mathrm{~mm}$. After construction, the masonry prisms were kept for 28 days curing, and then surface mortar layer was applied to the masonry prisms. The mortar layer thickness was 10 $\mathrm{mm}$. The masonry prisms were cured for another 28 days. Details of specimens are summarized in Table 4.

The axial compression tests were conducted in order to obtain the stress-strain curve of the specimens, according to BS EN 1052-1 [17]. The prisms consisted of five blocks and four joints of mortar as shown in Fig. 1. The prisms are cured for a period of 28 days under the moist burlap. The loading procedure is displacement-controlled monotonic loading at a rate of $5 \mathrm{~mm} / \mathrm{min}$ sampling frequency was $1 \mathrm{~Hz}$ in the data acquisition system. The applied load and displacement are measured by the Uniaxial testing machine load cell and stroke readings, respectively.

Table 3. Coconut coir added mortar properties

\begin{tabular}{llllll}
\hline Mortar properties & \multicolumn{5}{c}{ Coconut coir content } \\
& 0 & 0.125 & 0.25 & 0.5 & 0.75 \\
\hline Workability & & & & & \\
$\quad$ Water/binder ratio for slump $=160 \mathrm{~mm}$ & 0.62 & 0.76 & 0.80 & 0.89 & 0.95 \\
$\quad$ Flow value $(\mathrm{mm})$ & 174 & 171 & 160 & 152 & 144 \\
$\quad$ Setting time (min) & 234 & 231 & 228 & 220 & 215 \\
Density & & & & & \\
$\quad$ Bulk density $\left(\mathrm{kg} / \mathrm{m}^{3}\right)$ & 1987 & 1982 & 1957 & 1937 & 1920 \\
$\quad$ Dry density $\left(\mathrm{kg} / \mathrm{m}^{3}\right)$ & 1896 & 1866 & 1825 & 1793 & 1747 \\
Compression & & & & & \\
$\quad$ Strength $(\mathrm{MPa})$ & 2.79 & 2.85 & 2.92 & 2.95 & 2.63 \\
$\quad$ Fracture energy $\left(\mathrm{Nmm} / \mathrm{mm}^{2}\right)$ & 9.43 & 14.91 & 21.14 & 31.19 & 50.85 \\
Flexural bending & & & & & \\
$\quad$ Initial strength $(\mathrm{MPa})$ & 1.01 & 1.02 & 1.03 & 1.07 & 0.84 \\
$\quad$ Flexural ductility & 1.46 & 1.53 & 4.61 & 18.86 & 19.33 \\
Durability & & & & & \\
$\quad$ Water absorption rate $\left(\mathrm{kg} / \mathrm{m}^{3}\right)$ & 153.8 & 190.7 & 212.0 & 227.5 & 287.9 \\
$\quad$ Initial sorptivity $\left(\mathrm{mm} / \mathrm{min}^{1 / 2}\right)$ & 0.71 & 0.73 & 0.97 & 1.16 & 1.49 \\
$\quad$ Secondary sorptivity $\left(\mathrm{mm} / \mathrm{min}^{1 / 2}\right)$ & 0.56 & 0.59 & 0.61 & 0.73 & 1.21 \\
\hline
\end{tabular}




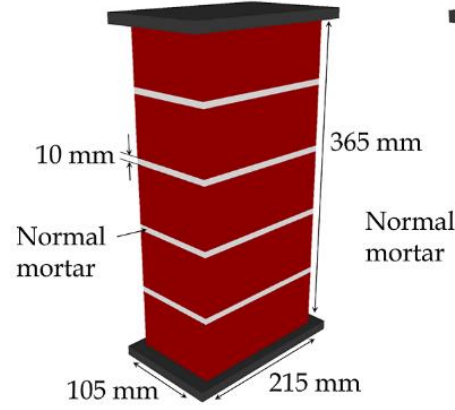

(a)

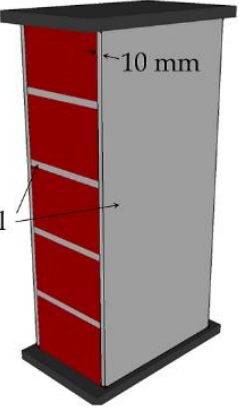

(b)

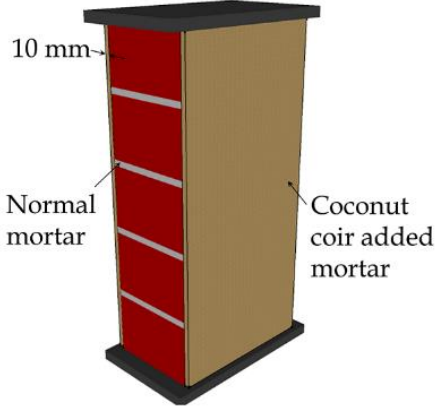

(c)

Fig. 1. Specimen types and dimension for compression test (a) reference specimen without surface finishing, (b) prism with normal mix surface plaster, and (c) prism with coconut coir added mortar mix for surface plaster

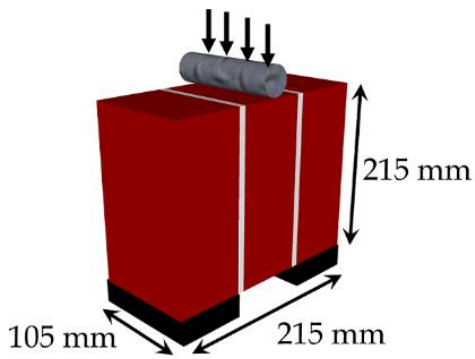

(a)

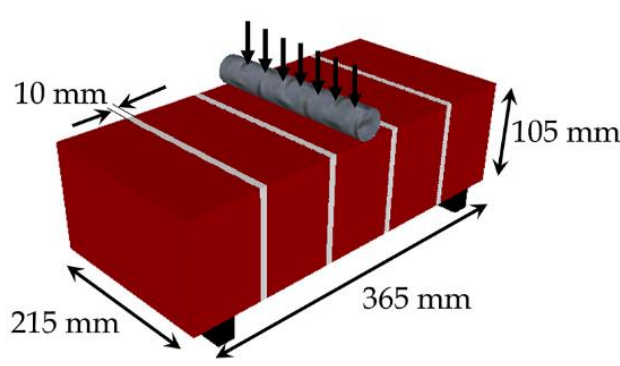

(b)

Fig. 2. Specimen types and dimension for (a) direct shear test, and (b) three-point flexural bending test

Table 4. Detail of test specimens

\begin{tabular}{|c|c|c|c|c|c|}
\hline \multirow[t]{2}{*}{ Specimen } & \multirow[t]{2}{*}{ Surface finishing } & \multicolumn{3}{|c|}{ Dimensions } & \multirow{2}{*}{$\begin{array}{l}\text { No of } \\
\text { specimen }\end{array}$} \\
\hline & & Length & Width & Height & \\
\hline \multirow{2}{*}{$\begin{array}{l}\text { Prism for } \\
\text { compression }\end{array}$} & - & 215 & 105 & 365 & 3 \\
\hline & $\begin{array}{l}\text { Plain mortar and } 0.125,0.25,0.50,0.75 \% \\
\text { coconut coir } \mathrm{r} / \mathrm{f} \text { mortar }\end{array}$ & 215 & $125^{1}$ & 365 & 15 (3 each) \\
\hline \multirow[t]{2}{*}{ Triplet for shear } & - & 215 & 105 & 215 & 3 \\
\hline & $\begin{array}{l}\text { Plain mortar and } 0.125,0.25,0.50,0.75 \% \\
\text { coconut coir r/f mortar }\end{array}$ & 215 & $125^{1}$ & 215 & 15 (3 each) \\
\hline \multirow{2}{*}{$\begin{array}{l}\text { Prism for flexural } \\
\text { bending }\end{array}$} & - & 365 & 215 & 105 & 3 \\
\hline & $\begin{array}{l}\text { Plain mortar and } 0.125,0.25,0.50,0.75 \% \\
\text { coconut coir r/f mortar }\end{array}$ & 365 & 215 & $125^{1}$ & 15 (3 each) \\
\hline
\end{tabular}

${ }^{1} 10 \mathrm{~mm}$ surface finishing in both side of the masonry

Widely used triplet test has been adopted for determination of shear strength according to BS EN 1052-3 [18]. The prisms consisted of three blocks and two joints of mortar as shown in Fig. 2(a). The triplet shear tests are performed while subjected to zero axial pre-compressive loads. The load is applied at a rate of $2 \mathrm{~mm} / \mathrm{min}$ under displacement control. To determine the flexural bending behavior, the masonry prisms are loaded under three pin loading method according to BS EN 10522 [19] as shown in Fig. 2(b). The loading force is applied monotonically in the middle of the prism. The testing criteria and loading displacement rates are similar to the direct shear test. 


\section{Result and discussion}

\subsection{Pre-crack behavior}

The strength values obtained for compression, shear bond and flexural tensile test on masonry without surface plaster and with surface plaster, including at various fractions of coconut coir are summarized in Table 5.

According to the results obtained, even though mortar gave additional compressive strength for masonry, the addition of coconut coir in the mortar mix does not affect the compressive strength. Generally, strong masonry unit and weak surface plastering mortar used in masonry and therefore compressive strength improvement not expected due to surface mortar application. However, in this experiment, surface plastering mortar strength almost $75 \%$ of brick strength and even higher than masonry strength. Therefore, application of surface plastering provides an additional $8 \%$ strength for masonry, compared with those of plain masonry. According to Erdogmus [20], the inclusion of fiber in the mortar increases the air content of the mix and due to this, the compressive strength of the mortar reduced. Here also, it is observed that the addition of coconut coir in the mix slightly reduced the compressive strength of masonry prisms. In the case of shear and flexural bending, even though mortar gave additional strength to masonry, the variation of the shear and flexural tensile strength is not showing much significant change with the addition of the coconut coir to the plaster.

Table 5. Pre-crack strength of masonry (standard deviation shown in bracket)

\begin{tabular}{lccc}
\hline \multirow{2}{*}{$\begin{array}{l}\text { Coconut coir } \\
\text { content }(\%)\end{array}$} & \multicolumn{3}{c}{ Strength $(\mathrm{MPa})$} \\
\cline { 2 - 4 } Ref & Compressive & Shear & Flexural \\
0 & $1.01_{(0.067)}$ & $0.18_{(0.024)}$ & $0.35_{(0.060)}$ \\
0.125 & $1.09_{(0.088)}$ & $0.23_{(0.024)}$ & $0.48_{(0.035)}$ \\
0.250 & $1.06_{(0.017)}$ & $0.24_{(0.011)}$ & $0.52_{(0.051)}$ \\
$0.500_{0}$ & $1.06_{(0.038)}$ & $0.25_{(0.032)}$ & $0.50_{(0.065)}$ \\
$0.750^{10}$ & $1.07_{(0.083)}$ & $0_{(0.005)}$ & $0.53_{(0.058)}$ \\
\hline
\end{tabular}

\subsection{Post-crack behavior}

\subsubsection{Compression}

In this testing, mortar used for joints are weaker than brick unit, prisms experienced crushing the mortar and it caused splitting of the brick face to occur. As load continued, the prism broke in sperate pieced along the vertical cracks as shown in Fig. 3.

The stress-strain curves of tested specimens are shown in Fig. 4. Even though pre-peak behavior is similar for both unreinforced and coconut coir mortar reinforced masonry prisms, post-peak behavior reveals significant variation in compression. Prisms without surface finishing and with plain surface finishing experienced a brittle failure and sudden drop in their load-carrying capacity was observed. For prisms with coconut coir reinforced surface finishing, the gradual change in the load-carrying capacity was observed after peak load. The results showed that the post peak strength of coconut coir-reinforced mortar increased with increasing percentage of coconut coir. The ductile behavior of coconut coir reinforced mortar, which can control the cracking widening may improve the ductility of masonry prisms and improve the post peak-load behavior. Improving the good bond between coir reinforced mortar and the masonry surface may be another reason for the improvement in post-peak behavior.

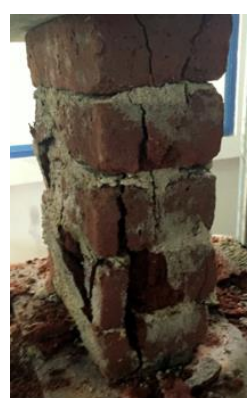

(a)

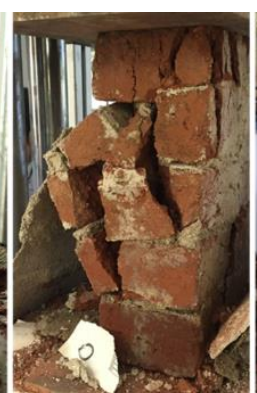

(b)

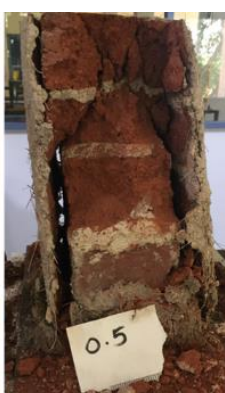

(c)
Fig. 3. Behavior of masonry prisms under compression (a) prism without plaster (b) prism with a standard plaster (c) prism with $0.5 \%$ coconut coir added plaster 

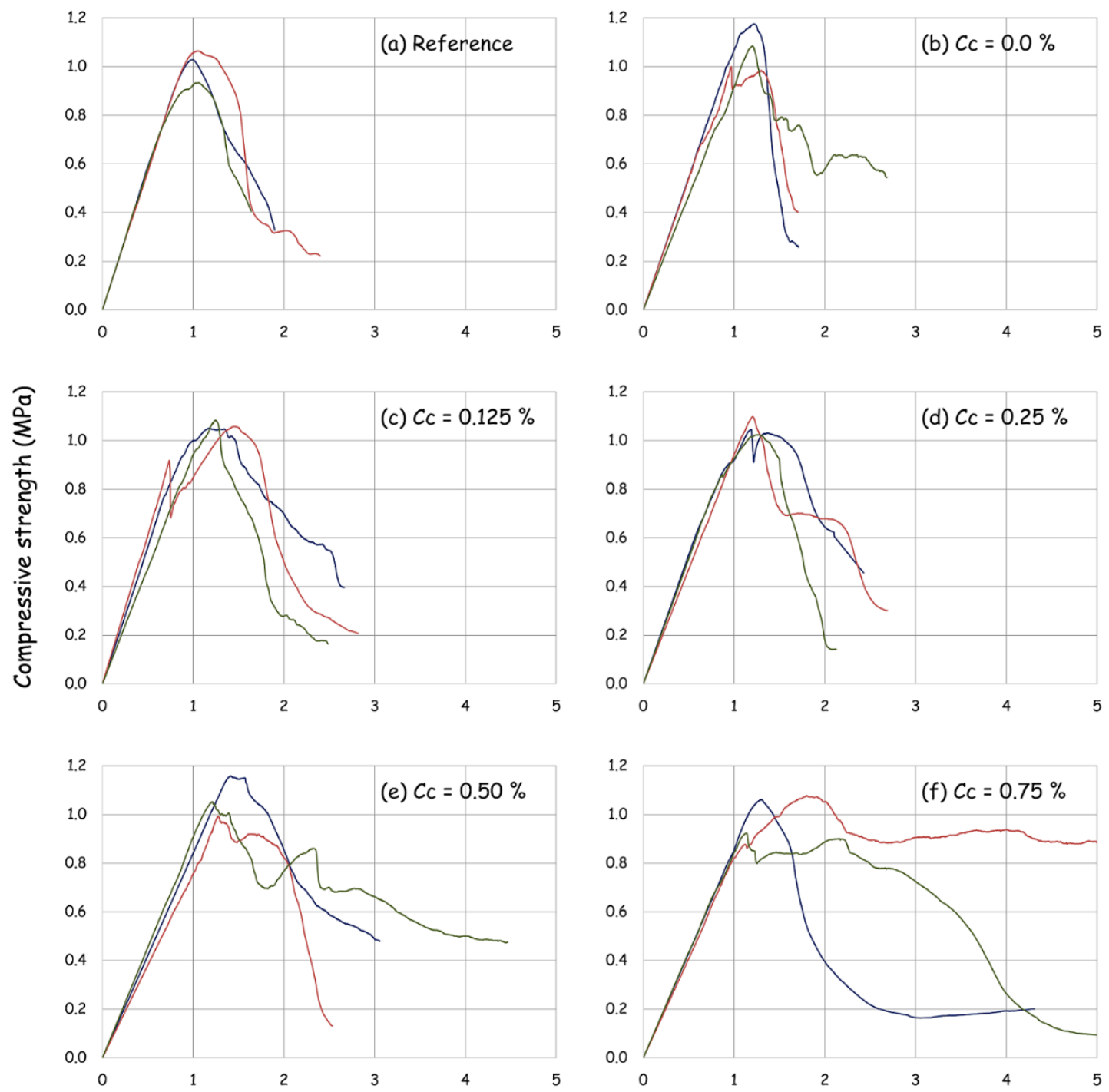

\section{Strain (\%)}

Fig. 4. The stress-strain response of the masonry prism under compression

The compressive fracture energy is defined as the post-crack energy absorption ability of the structure under compression and it represents the energy that the structure will absorb during failure in compression [21]. The compressive fracture energy $(\mathrm{J})$, was calculated as the area under the compressive force-displacement curve up to a defined post crack load of one third peak load as shown in Fig. 5(a). The compressive fracture energy of the masonry prisms is summarized in Fig. 5(b). The result shows the addition of coconut coir results in greater energy absorption and improves post-peak behavior.

\subsubsection{Direct shear}

Fig. 6 shows the masonry triplet at the end of the test. In the masonry triplet without mortar case, the triplets split into two pieces after the crack occurred and no residual strength was left. In the masonry triplet with coconut coir reinforced mortar case, on the other hand, cracks appear progressively. It sustained additional deformation before totally separated. 


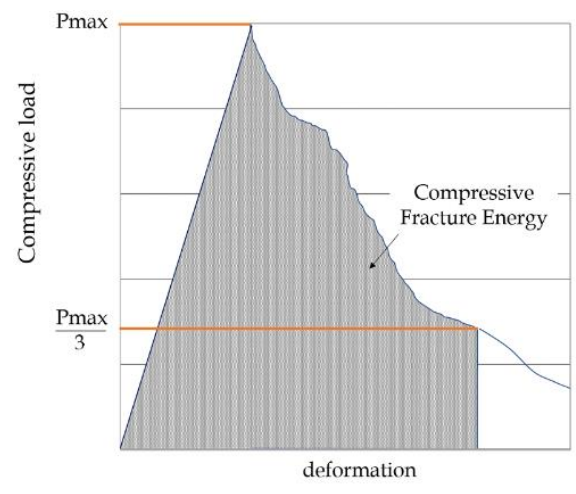

(a)

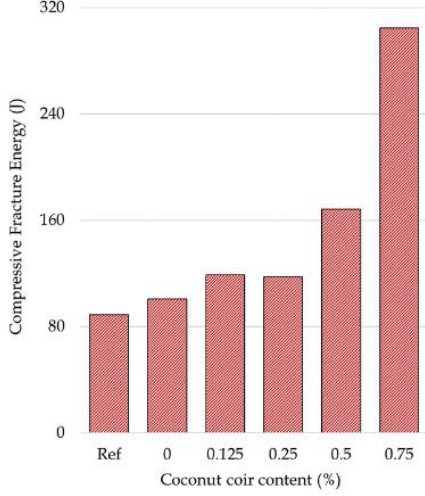

(b)

Fig. 5. (a) Definition of compressive fracture energy (b) the average values of compressive fracture energy

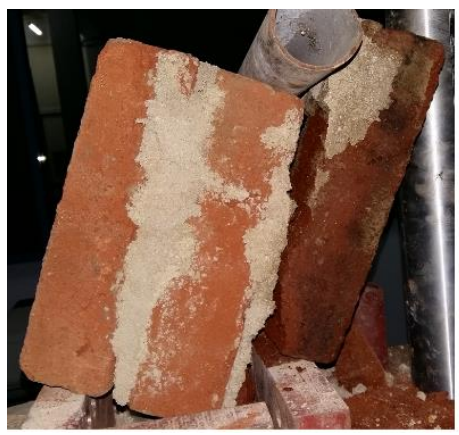

(a)

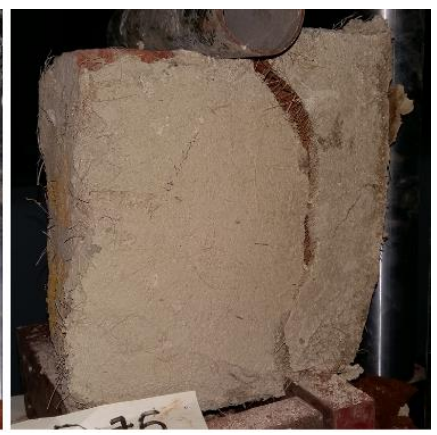

(b)

Fig. 6. Failure patterns of masonry triplet (a) without mortar, and (b) mortar with $0.75 \%$ coconut coir

The values of the normalized post-peak loading (with respect to Pmax) are reported in Fig. 7. Conversely, the difference between the post-peak deflection $(\delta)$ and deflection at peak load $(\delta p)$ is on the horizontal axis. All the post-peak diagrams are limited to the value $\delta$ - $\delta$ p equal to $1.5 \mathrm{~mm}$. Masonry triplet without surface finishing showed the sudden drop in load-carrying capacity after peak load. However, for triplets with surface finishing, had a load-carrying capacity after peak load and showed improvement in load-carrying capacity for increased coconut coir increases in mortar.

The post-crack energy was quantified by calculating the area $A_{F}$ delimited by the post-peak curves as shown in Fig. 8(a). Ductility is defined as the ratio between the shear deformation at $60 \%$ load-carrying capacity of peak load in the postcrack region and deformation at yield. The average value of $A_{F}$ and ductility, measured in the six types of masonry prisms are compared in Fig. 8(b) and Fig. 8(c).
As seen in Fig. 8, both $A_{F}$ and ductility of masonry triplets increased with higher coconut coir fractions as compared with the masonry triplet having control mortar as surface finishing. Higher values were observed in $0.5 \%$ of coconut coir fraction and when coconut coir fraction is increased to $0.75 \%$, it shows reduction in $\mathrm{A}_{\mathrm{F}}$ and ductility values. The result shows the addition of coconut coir results in greater ductility and improves postpeak behavior. A possible reason for this improvement, after initial cracking, coconut coir resists and transfer the tensile stress developed in the failure surface. This is attributed to the ability of the coconut coir to distribute stresses and slow down the crack propagation process. As a result, masonry triplet with coconut coir behaves more ductile than that of the masonry triplet with control mortar as surface finishing or without surface finishing. 

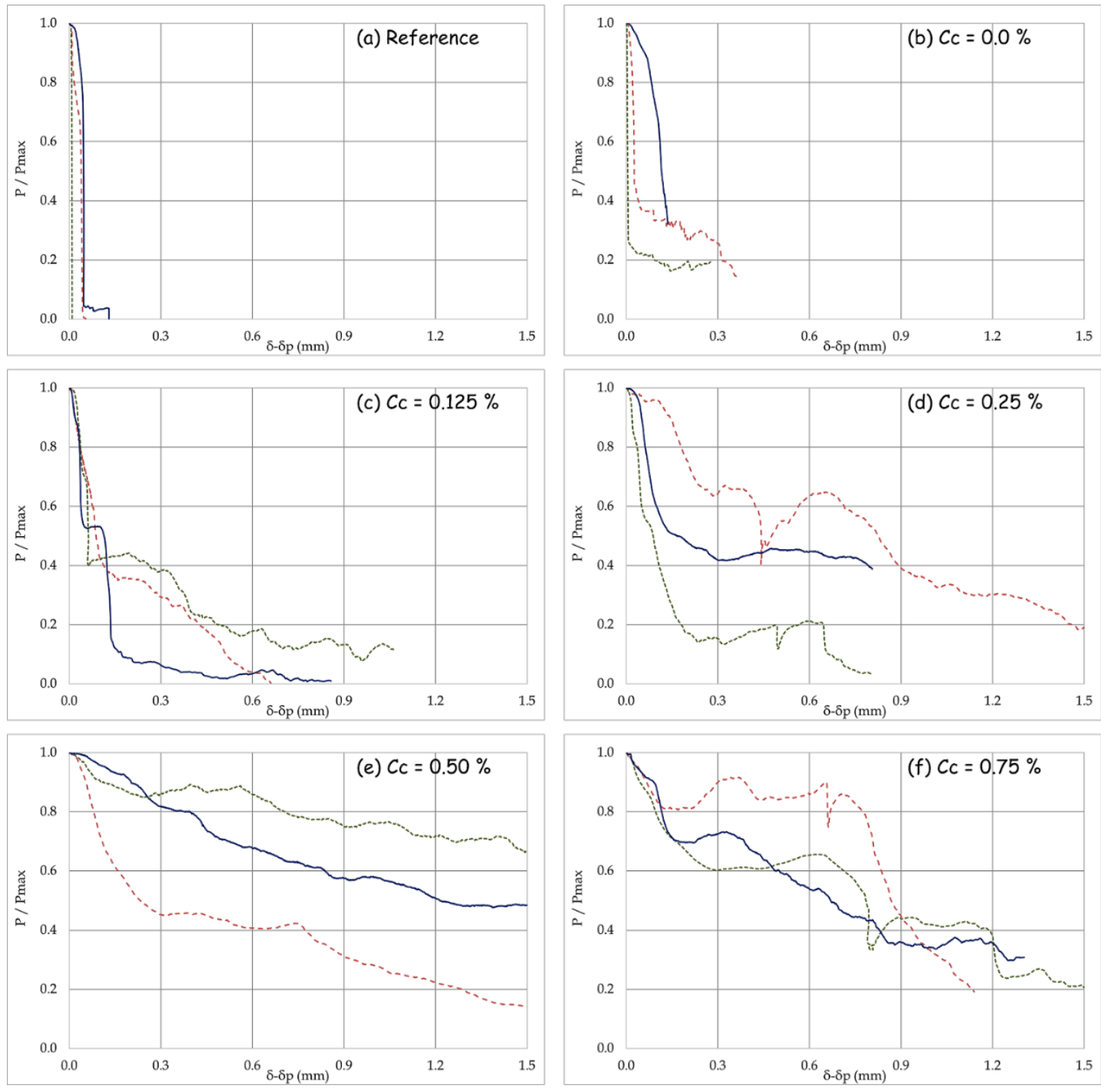

Fig. 7. The post-peak response of the masonry prism under direct shear

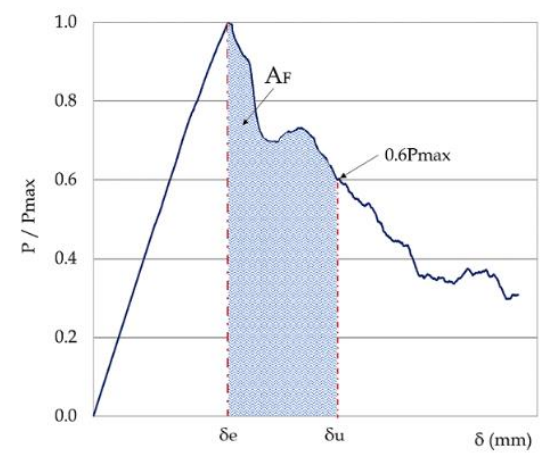

(a)

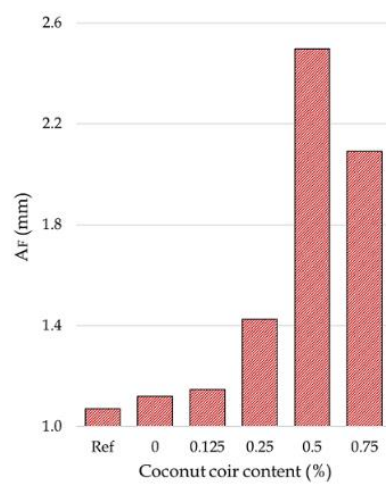

(b)

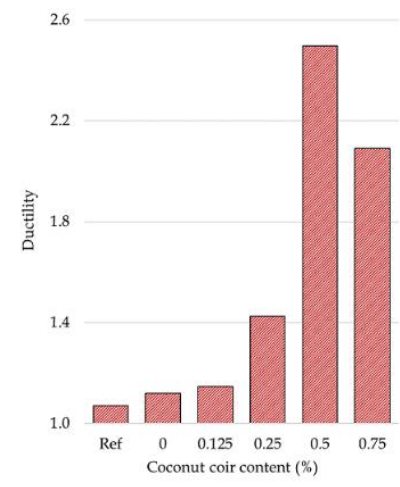

(c)

Fig. 8. (a) Definition of $A_{F}$ and ductility (b) the average values of $A_{F}$, and (c) ductility measured in the three-point bending tests 


\subsubsection{Flexural bending}

Fig. 9 shows the masonry prisms failure during the test. Similar to the shear test, in the masonry prisms without mortar case, the prism splits into two pieces after the crack occurred. In the masonry prisms with mortar case, on the other hand, cracks appear progressively.

As mentioned earlier, in comparison with unreinforced mortar, using the coconut coir reinforced mortar does not increase flexural strength noticeably. Even though pre-peak behavior does not improve due the presence of coconut coir mortar reinforced masonry, the most significant enhancement is the improvement in post-cracking behavior. Toughness is the measure of energy absorbed by a specimen in undergoing a specified amount of post crack strain. In case of the coconut coir mortar reinforced masonry, post-peak strength degradation was more gradual than unreinforced masonry and it is indicating the addition of coconut coir have enhanced the toughness. To measure the post-peak behavior, the method proposed by Fantilli et al. [22] is presented. For this purpose, normalized applied force with respect to peak load (P/Pmax) curve starting from the mid-span deflection at peak load $(\delta-\delta$ p), reported in Fig. 10 was introduced. The post-peak curve is limited to the value $\delta$ - $\delta$ p equal to $1.0 \mathrm{~mm}$. In correspondence to this stage, there is no residual load resistance for masonry prisms without mortar and mortar with $0 \%$ coconut coir fraction. However, load-carrying capacity after the peak load of masonry prisms with coconut coir reinforced mortar improved with an increase in the coconut coir fraction in mortar.

Post-crack fracture energy was quantified by calculating the area AF delimited by the post-peak curves as shown in Fig. 11(a). If this value is divided by the area AI (delimited by the pre-crack curves), a sort of fracture toughness in bending was attained. The average value of AF and toughness, measured in the six types of masonry prisms are compared in Fig. 11(b) and Fig. 11(c). The results show that the value of ductility and fracture toughness increased with an increase in the fraction of coconut coir. In particular, the values of $\mathrm{AF}$ and toughness calculated for masonry prisms with
$0.75 \%$ coconut coir mortar are about 10 times higher than that of masonry prisms with control mortar. The results suggest that the presence of coconut coir in the surface plastering mortar promoted a significant increase in residual strength, fracture energy, and toughness.

\subsubsection{Summary}

Various standard tests were considered on masonry prisms with different fraction coconut coir reinforced mortar, with a view to understand the behavior of masonry under compression, shear, and flexural bending. Mechanical properties of masonry prisms are summarized in Fig. 12.

\section{Conclusion}

From the experimental program conducted and the results obtained, the following conclusions can be drawn:

- The strength of coconut coir mortar reinforced masonry does not differ from those of masonry with control mortar.

- In masonry prisms with $0.75 \%$ of coconut coir equivalent mass of cement in mortar, the compressive fracture energy increases by three times.

- Optimum direct shear performance observed for masonry triplet with $0.5 \%$ of coconut coir in a mortar and the ductility in shear increased by 2.3 times.

- Optimum flexural bending performance observed for masonry prism with $0.75 \%$ of coconut coir in a mortar and the flexural toughness in bending increased by 9.5 times.

Indicate that 50 percent of coconut coir fiber content was found to be the optimum percentage as it exhibited highest compressive, shear and flexural strengths as indicated in Table 5. Although this technique shows an average performance, due to the facts of low cost, high availability and relative simplicity of technique, this method may potentially be able to use to prevent the brittle collapse and helps to confining the masonry walls.

When the coconut coir mortar is applied all over the wall surface, it ends up developing a strong matrix and therefore it increases the shear and 


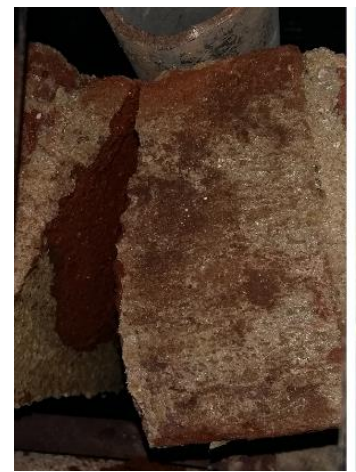

(a)

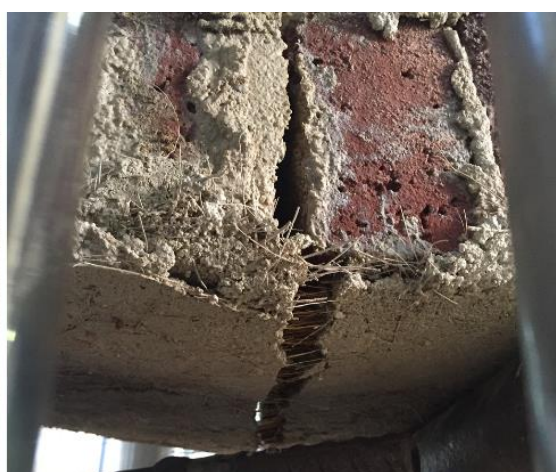

(b)

Fig. 9. Failure patterns of masonry prism (a) without mortar, and (b) mortar with $0.75 \%$ coconut coir
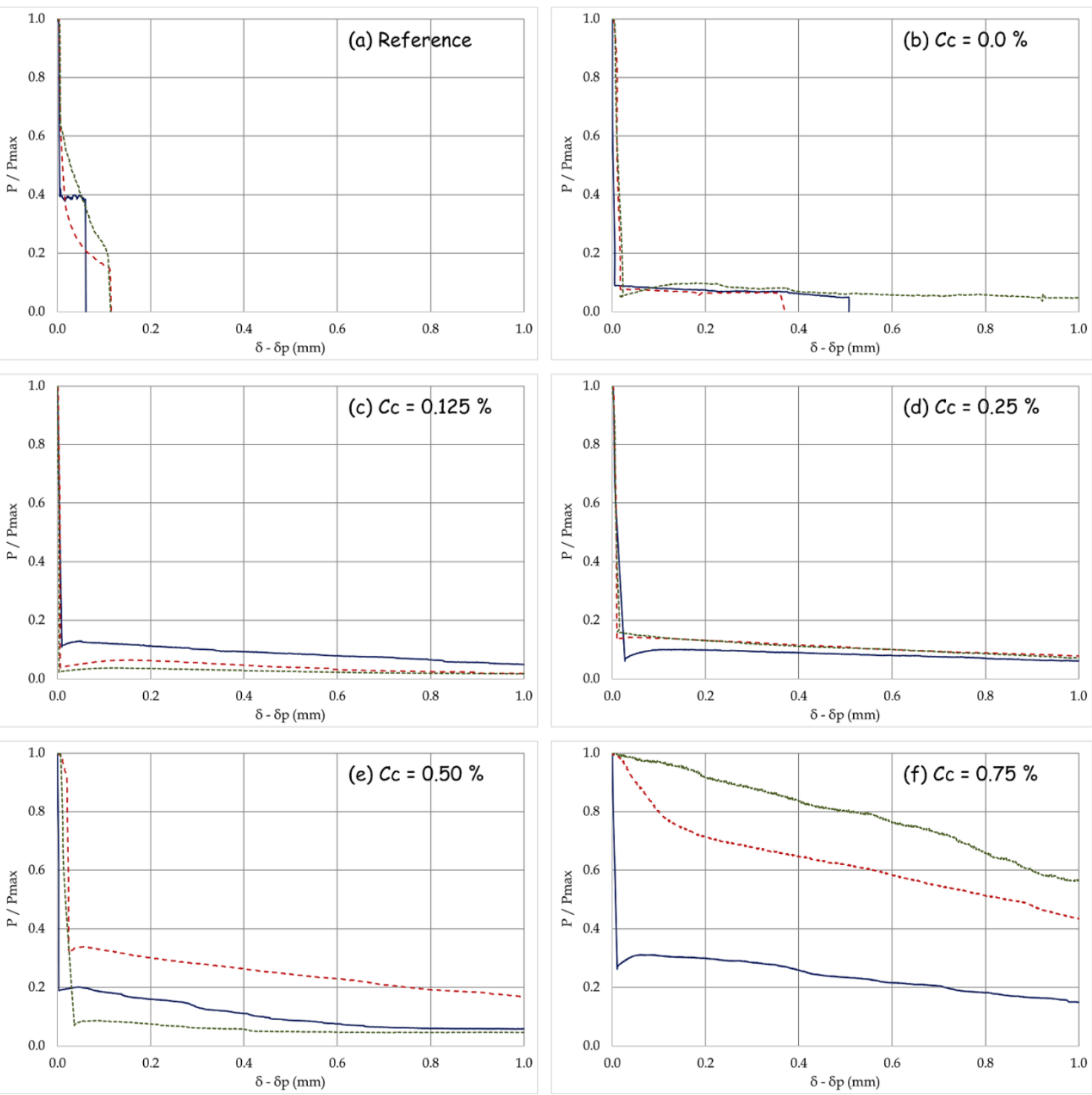

Fig. 10. The post-peak response of the masonry prism under flexural bending 


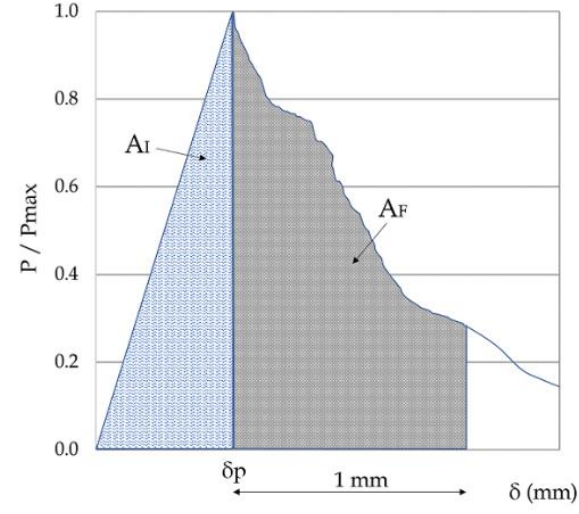

(a)

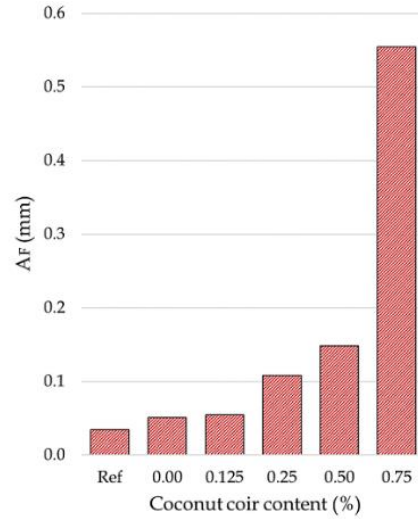

(b)

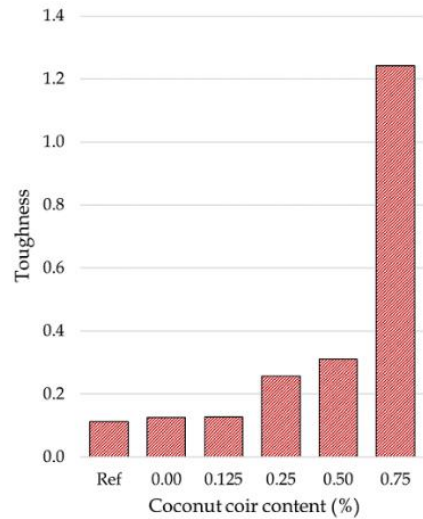

(c)

Fig. 11. (a) Definition of $A_{F}$ and toughness (b) the average values of $A_{F}$, and (c) toughness measured in the three-point bending tests

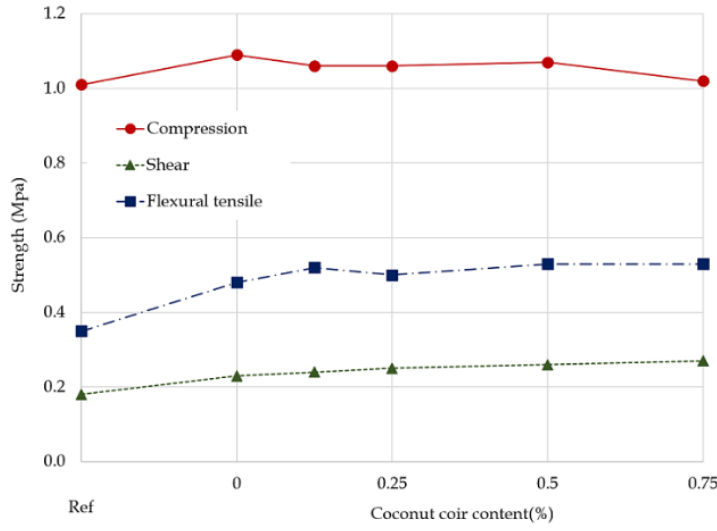

(a) Strength properties

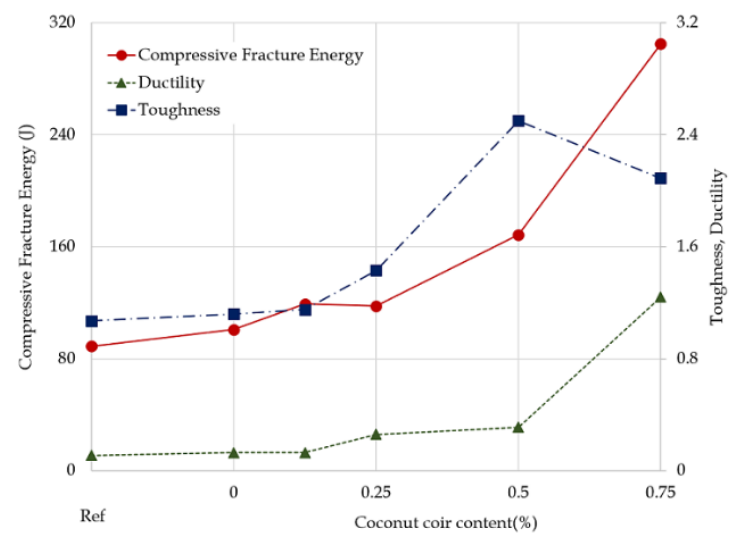

(b) Post-peak properties

Fig. 12. Summary of pre- and post-peak properties of masonry prisms

flexural capacity of the masonry wall against the external forces. The coconut coir mortar grips the wall and acts as a protection layer. Therefore, this strengthened method may show larger improvement when acting on the wall than on single masonry prisms. Therefore, further experimental works need to be performed on masonry wall or house models to check the full capacity of this reinforcement technique. However, this study provides a strong foundation for further development of natural fiber reinforced mortar for the strengthening of low-strength masonry structures.

\section{Acknowledgments}

The author expresses his sincere gratitude for the support given by Building Material and
Construction Laboratory, Department of Civil and Environmental Engineering, Faculty of Engineering, University of Ruhuna. The author is grateful for the assistance of Mr. Bhasura H.M.P., Department of Civil and Environmental Engineering, Faculty of Engineering, University of Ruhuna, for his valuable support to carry out the experimental works

\section{References}

[1] Muller U, Miccoli L, Fontana P (2016) Development of a lime based grout for cracks repair in earthen constructions. Construction and Building Materials 110: 323-332.

[2] Ismail N, Ingham JM (2012) Cyclic out-of-plane behaviour of slender clay brick masonry walls 
seismically strengthened using posttensioning. Journal of Structural Engineering 138: 1255-1266.

[3] Kadam SB, Singh Y, Li B (2014) Strengthening of unreinforced masonry using welded wire mesh and micro-concrete - behaviour under in-plane action. Construction and Building Materials 54: 247-257.

[4] Ismail N, Ingham JM (2016) In-plane and out-ofplane testing of masonry walls strengthened using polymer textile reinforced mortar. Engineering Structures 118: 167-177.

[5] Tetley R, Madabhushi G. Vulnerability of adobe buildings under earthquake loading. Proceeding of the 4th Conference Earthquake Geotechnical Engineering, 25-28 June, 2007, Thessaloniki, Greece.

[6] Sathiparan N, Mayorca P, Meguro K (2012) Shake table tests on one-quarter scale models of masonry houses retrofitted with PP-band mesh. Earthquake Spectra 28: 277-299.

[7] Meguro K, Soti R, Sathiparan N, Numada M (2012) Dynamic testing of masonry houses retrofitting by bamboo band meshes. Journal of Japan Society of Civil Engineers (Structural Engineering and Earthquake Engineering) 68: 760765.

[8] Sathiparan N (2015) Mesh type seismic retrofitting for masonry structures: critical issues and possible strategies. European Journal of Environmental and Civil Engineering 19: 1136-1154.

[9] Maalej M, Lin VWJ, Nguyen MP, Quek ST (2010) Engineered cementitious composites for effective strengthening of unreinforced masonry walls. Engineering Structures 32: 2432-2439.

[10] Kyriakides MA, Billington SL (2014) Behavior of unreinforced masonry prisms and beams retrofitted with engineered cementitious composites. Materials and Structures 47: 1573-1587.

[11] Dehghani A, Nateghi-Alahi F, Fischer G (2015) Engineered cementitious composites for strengthening masonry infilled reinforced concrete frames. Engineering Structures 105: 197-208.

[12] Najafgholipour MA, Dehghan SM, Mirzaee AR, Aghaei AA (2016) Experimental investigation on flexural behavior of masonry prisms strengthened by fiber-reinforced mortar layer. Iranian Journal of Science and Technology, Transactions of Civil Engineering 40: 277-286.

[13] Specification for cement blocks: part 1: Requirements SLS 855 (1989) Sri Lanka Standards Institution, Colombo, Sri Lanka.
[14] Das Gupta NC, Paramsivam P, Lee SL (1978) Mechanical properties of coir reinforced cement pastes composites. Housing Science 2: 391-406.

[15] CEN. Eurocode 6: Design of masonry structures Part 1-1 (2005) General rules for reinforced and unreinforced masonry structures. European Committee for Standardization, Brussels, Belgium.

[16] Sathiparan N, Rupasinghe MN, Bhasura HMP (2017) Performance of coconut coir reinforced hydraulic cement mortar for surface plastering application. Construction and Building Materials 142: 23-30.

[17] BS EN 1052-1 (1999) Methods of test for masonry - Part 1: Determination of compressive strength, British Standards Institution, London, UK.

[18] BS EN 1052-3 (2002) Methods of test for masonry - part 3: determination of initial shear strength, British Standards Institution, London, UK.

[19] BS EN 1052-2 (1999) Methods of test for masonry - part 2: determination of flexural strength, British Standards Institution, London, UK.

[20] Erdogmus E (2015) Use of fiber-reinforced cements in masonry construction and structural rehabilitation. Fibers 3: 41-63.

[21] Merta I, Tschegg EK (2013) Fracture energy of natural fibre reinforced concrete. Construction and Building Materials 40: 991-997.

[22] Fantilli AP, Sicardi S, Dotti F (2017) The use of wool as fiber-reinforcement in cement-based mortar. Construction and Building Materials 139: 562-569. 